Diabetologia 9, 130-134 (1973)

(C) by Springer-Verlag 1973

\title{
Possible Contribution of Renal Gluconeogenesis to the Development of N-Monomethylacetamide-Induced Hyperglycemia in the Rat * **
}

\author{
P.B. Iynedjian \\ Institut de Pharmacologie, Université de Lausanne, Lausanne, Switzerland.
}

Received: September 11, 1972; accepted: December 14, 1972

\begin{abstract}
Summary. The gluconeogenic capacity of the rat kidney cortex in the experimental diabetes induced by N-monomethylacetamide (NMMAA) was studied. Renal cortical slices from NMMAA diabetic rats synthesized glucose at an accelerated rate from pyruvate, $\alpha$-ketoglutarate or fructose, but not from glutamine. In contrast, NMMAA added to the incubation medium inhibited glucose production by slices from normal rats, irrespective of the substrate used. To evaluate the role of renal gluconeogenesis in vivo, the effect of bilateral nephrectomy on the development of NMMAA-induced hyperglycemia was studied. The hyperglycemic effect of NMMAA was markedly blunted in nephrectomized rats. On the other hand,
\end{abstract}

ureteral ligation after NMMAA administration did not prevent a normal rise in blood glucose. These data are consistent with the view that the stimulated renal gluconeogenesis in the NMMAA diabetic rat represents a significant proportion of total carbohydrate production in the body, and contributes to the elevation of the blood glucose level.

Key words: Gluconeogenesis, renal gluconeogenesis, $\mathrm{N}$-monomethylacetamide, experimental diabetes, kidney and carbohydrate metabolism, nephrectomy, ureteral ligation.
The renal cortex is endowed with all the enzymes necessary for the production of glucose from glucogenic substrates [23]. While the capacity of the kidney to produce glucose in vitro has been well established since it was first demonstrated by Benoy and Elliott [3], the role of the kidney in blood glucose homeostasis in vivo has not been definitely settled.

It has been repeatedly shown in the rat that the gluconeogenic capacity of the kidney cortex is enhanced in alloxan diabetes $[26,14,15]$. Moreover, there is some evidence that in this condition the kidneys might play an important role in the overall production of glucose in the body [24].

In the present work we investigated a possible role of renal gluconeogenesis in the experimental diabetes induced by $\mathrm{N}$-monomethylacetamide (NMMAA). In the rat, the administration of a single large dose of this substance is followed by a progressive increase of the blood glucose level until death [9]. Despite considerable hyperglycemia, the suppressible insulin-like activity (SILA) in the serum of intoxicated animals remains very low [9], indicating a deficiency of biologically active insulin. The experiments reported here were undertaken to study (a) the effect of NMMAA intoxication on the gluconeogenic capacity of the renal cortex; and (b) the effect of nephrectomy on the development of NMMAA-induced hyperglycemia, assuming that if the kidneys synthesize glucose in excess of their requirement, removal of the organs could depress the blood glucose level.

* Supported by Fonds National Suisse de la Recherche Scientifique, Grants no 3516 and no 3.370.70.

** Parts of this work have been published in abstract form (Experientia 26, 691 (1970).

\section{Material and Methods}

Male Wistar type rats (purchased from Tierzucht Institut der Universität Zürich) weighing 180 to $280 \mathrm{~g}$ were used in all experiments. They were fed ad libitum on rat chow (Altromin GmbH, Lage, F. R. Germany) up to the time stated under results for each experiment. $\mathrm{N}$-monomethylacetamide (Fluka AG, Buchs, Switzerland) was melted at $35^{\circ} \mathrm{C}$ and given undiluted by stomach tube.

In vitro gluconeogenesis. The rats were stunned by a sharp blow on the head and decapitated, and the kidneys were quickly removed. Cortical slices of kidneys of control and treated rats were cut by hand by the method of Deutsch [5] and washed for about $20 \mathrm{~min}$ in ice-cold $0.9 \%$ $\mathrm{NaCl}$ solution. The slices from each rat were then distributed into three to four 25-ml Erlenmeyer flasks, each containing $4 \mathrm{ml}$ Krebs-Henseleit solution, pH 7.4 [17], with the appropriate substrate $(10 \mathrm{mM})$, and into two additional flasks without substrate. Two to three slices (1 - $3 \mathrm{mg}$ dry wt) were placed in each flask, and incubated for $1 \mathrm{~h}$ at $40^{\circ} \mathrm{C}$ in a Dubnoff metabolic shaker. The flasks were gassed with $\mathrm{O}_{2}+\mathrm{CO}_{2}(95: 5)$ throughout the incubation. After incubation, the slices were placed into tared mortars, dried at $120^{\circ} \mathrm{C}$ for $30 \mathrm{~h}$ and weighed. The incubation media were deproteinized by the addition of $1 / 10$ volume of $20 \%$ (W/W) $\mathrm{HClO}_{4}$, and the glucose concentration was determined by the glucose oxidase method. [11].

The production of glucose from a particular substrate was calculated for each animal by substracting the mean glucose production of the animal's slices incubated in substrate-free medium from that of its slices incubated in the presence of the substrate.

The substrates used were: Na pyruvate, $\alpha$-ketoglutaric acid (C.F. Boehringer \& Soehne GmbH, Mannheim, F.R. Germany), $\mathrm{L}(+)$ glutamine and $\mathrm{D}(-)$ fructose (Fluka AG, Buchs, Switzerland). A 1 M stock solution of $\alpha$-ketoglutaric acid was titrated to $\mathrm{pH} 7.4$ with $6 \mathrm{~N} \mathrm{NaOH}$ before addition to incubation medium.

Operations. Bilateral nephrectomy or ureteral ligation were performed under ether anesthesia, using a dorsal approach. Damage to the adrenal glands was carefully 
avoided. Controls wore sham-operated under strictly comparable conditions.

Blood glucose determinations. $10 \mu \mathrm{l}$ blood samples were obtained from the tail vein of conscious animals placed in restraining cages. The samples were deproteinized immediately with $100 \mu \mathrm{l}$ of ice-cold $2 \% \mathrm{HClO}_{4}$ and analyzed in duplicate with a glucose oxidase method using commercial kits ( $F$. Hoffmann - La Roche \& Co AG, Diagnostica, Schweizerhalle, Switzerland).

Expression of results. Numerical results are expressed as means \pm SEM with the number of observations in parentheses. Significance of differences was tested by conventional methods [25], assuming a normal distribution of the values.
$8 \mathrm{ml} / \mathrm{kg}$ body wt of NMMAA or water and deprived of food $12 \mathrm{~h}$ before sacrifice.

Renal cortical slices from treated rats produced significantly more glucose from pyruvate, $\alpha$-ketoglutarate and fructose than did slices from controls. On the other hand, gluconeogenesis from glutamine did not differ significantly between the two groups (Table 1). Immediately before sacrifice, the blood glucose concentration in the treated rats was $126 \pm 4.1 \mathrm{mg}$ per $100 \mathrm{ml}$, significantly different from $70 \pm 1.0 \mathrm{mg}$ per $100 \mathrm{ml}$ in the controls (Table 1).

Table 1. Effect of NMMAA administration on gluconeogenic capacity of rat renal cortex slices

\begin{tabular}{|c|c|c|c|c|c|}
\hline \multirow{2}{*}{ Substrate } & \multicolumn{2}{|c|}{ Glucose production } & \multirow{2}{*}{$\begin{array}{l}\text { Absolute } \\
\text { increase }\end{array}$} & \multirow{2}{*}{$\begin{array}{l}\text { Percent } \\
\text { increase }\end{array}$} & \multirow{2}{*}{$\begin{array}{l}\text { Significance } \\
\text { of difference }\end{array}$} \\
\hline & control & NMMAA-fed & & & \\
\hline & \multicolumn{4}{|c|}{ umoles $\cdot g$ dry $w^{-1} \cdot h^{-1}$} & $\mathrm{P}$ \\
\hline $\operatorname{non} \theta$ & $21 \pm 0.5(30)$ & $32 \pm 1.3(28)$ & $11 \pm 1.4$ & 52 & $<0.001$ \\
\hline pyruvate & $296 \pm 9.4(8)$ & $363 \pm 11.6(7)$ & $66 \pm 14.7$ & 22 & $<0.001$ \\
\hline glutamine & $130 \pm 3.7(8)$ & $138 \pm 8.0(7)$ & $8 \pm 8.5$ & 6 & NS \\
\hline$\alpha-K G$ & $172 \pm 5.0(7)$ & $235 \pm 7.7(7)$ & $63 \pm 9.2$ & 36 & $<0.001$ \\
\hline \multirow[t]{3}{*}{ fructose } & $599 \pm 12.4(7)$ & $682 \pm 13.4(7)$ & $83 \pm 18.3$ & 14 & $<0.001$ \\
\hline & \multicolumn{2}{|c|}{ Blood glucose concentration } & & & \\
\hline & $\begin{array}{c}\text { mg per } 100 \mathrm{ml} \\
70 \pm 1.0(30)\end{array}$ & $126 \pm 4.1(28)$ & $56 \pm 4.1$ & 80 & $<0.001$ \\
\hline
\end{tabular}

Table 2. Effect of NMMAA added to incubation medium on gluconeogenic capacity of renal cortex slices from normal rats

\begin{tabular}{|c|c|c|c|}
\hline \multirow[b]{2}{*}{ Substrate } & \multicolumn{2}{|c|}{ Total glucose production } & \multirow[b]{2}{*}{$\begin{array}{l}\text { Percent } \\
\text { inhibition }\end{array}$} \\
\hline & $\begin{array}{l}\text { Krebs- } \\
\text { Henseleit } \\
\text { medium }\end{array}$ & $\begin{array}{l}\text { Krebs- } \\
\text { Henseleit } \\
\text { medium }+ \\
\text { NMMAA }\end{array}$ & \\
\hline & \multicolumn{2}{|c|}{$\mu$ moles $\cdot g$ dry wit-1 $1.5 \mathrm{~h}^{-1}$} & \\
\hline $\begin{array}{l}\text { glutamine } \\
\alpha-K G\end{array}$ & $\begin{array}{l}240 \pm 7.7(6) \\
258 \pm 4.1(6)\end{array}$ & $\begin{array}{l}213 \pm 7.0(6) \\
235 \pm 3.9(6)\end{array}$ & $\begin{array}{r}10.3 \pm 1.39(6) \\
9.2 \pm 1.80(6)\end{array}$ \\
\hline
\end{tabular}

Substrate concentration: $10 \mathrm{mM}$. NMMAA concentration: $50 \mathrm{mM}$
The possibility that NMMAA per se stimulated gluconeogenesis by a direct action on renal cortical tissue was investigated. Kidney cortex slices from 12 normal rats fasted for $12 \mathrm{~h}$ were used. Half the slices from each rat were incubated in the usual medium containing a gluconeogenic substrate and half in a medium containing the same substrate and $50 \mathrm{mmoles} / \mathrm{l}$ $\mathrm{NMMAA}^{1}$, but only $22.5 \mathrm{meq} / 1 \mathrm{HCO}_{3^{-}}$instead of 25 in order to keep the $\mathrm{pH}$ at 7.4. Values in table 2 refer to total glucose production in either medium, in the presence of glutamine or $\alpha$-ketoglutarate, during a 90 min incubation. NMMAA added to the medium

Table 3. Effect of nephrectomy and ureteral ligation on blood glucose of NMMAA intoxicated rats

\begin{tabular}{|c|c|c|c|}
\hline Group & $\begin{array}{l}\text { Hours after NMMAA } \\
8\end{array}$ & 12 & 16 \\
\hline & blood glucose $\mathrm{mg}$ per $100 \mathrm{ml}$ & & \\
\hline Control & $165 \pm 12.4(16)$ NS & $188 \pm 10.8(26) \mathrm{NS}$ & $220 \pm 9.0(32) p<0.001$ \\
\hline Ureteral ligation & $152 \pm 12.4(12)^{1 \times D}$ & $161 \pm 12.5(16)^{183}$ & $154 \pm 12.2(16)^{2}$ \\
\hline Nephrectomy & $115 \pm 4.4(13)^{p<0.01}$ & $95 \pm 9.2(12)^{p}$ & $73 \pm 9.7(15)^{\mathrm{p}}$ \\
\hline
\end{tabular}

The rats were tube-fed $10 \mathrm{mI}$ NMMAA $/ \mathrm{kg}$ body wt and deprived of food for the remainder of the experiment. Surgery was performed $2 \mathrm{~h}$ after NMMAA administration.

\section{Results}

1. Effect of NMMAA intoxication on gluconeogenic capacity of renal cortex

Table 1 summarizes the results obtained in 28 treated rats and 30 controls. The animals were tube-fed significantly $(p<0.001)$ inhibited glucose formation by approximately 10 percent with each substrate.

1 The serum NMMAA concentration 15 min after an oral dose of $8 \mathrm{ml} / \mathrm{kg}$ body wt has been estimated to be approximately 75 mmoles/l [9]. 
2. Effect of nephrectomy or ureteral ligation on NMMAA-induced hyperglycemia

Figure 1 illustrates the time course of the development of hyperglycemia in nephrectomized rats intoxicated by $10 \mathrm{ml} / \mathrm{kg}$ body wt of NMIMAA. The animals were freely fed until operation which was performed $14 \mathrm{~h}$ before NMMAA administration. Solid food was then withdrawn. The blood glucose concentration was slightly, but significantly lower in the nephrectomized rats than in the controls immediately before giving NMMAA. Thereafter, the magnitude of the difference between the two groups largely increased, as the blood glucose concentration rose steadily in the controls, but remained at relatively low levels in the nephrectomized animals (Fig. 1).

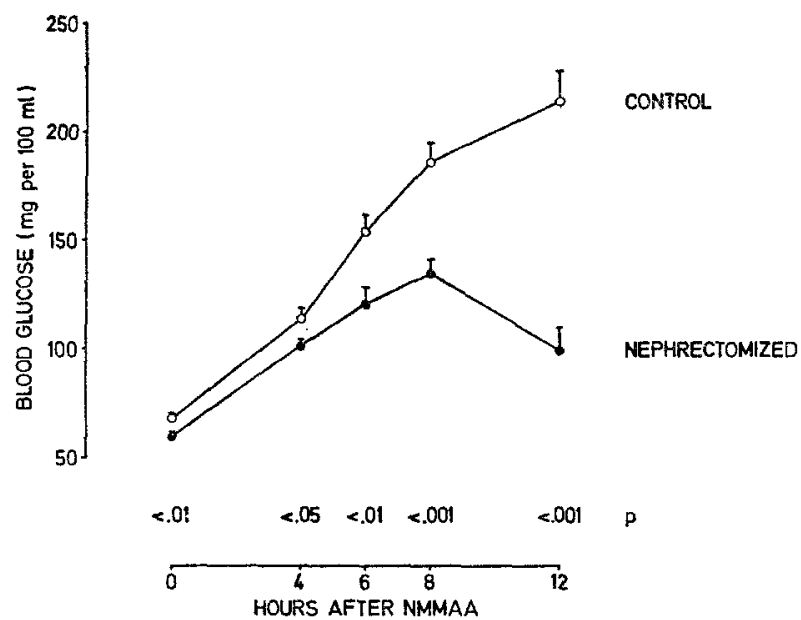

Fig. 1. Effect of NMMAA on blood glucose of nephrectomized rats. The rats were nephrectomized or sham-operated and deprived of food $14 \mathrm{~h}$ before oral administration of $10 \mathrm{ml}$ NMMAA $/ \mathrm{kg}$ body wt. Each point is the mean of at least 10 observations. $P$ refers to the differences in the means between the two groups. The mean survival time following NMMAA administration was $17.5 \pm 1.20 \mathrm{~h}$ in the controls and $15.5 \pm 0.60 \mathrm{~h}$ in the nephrectomized rats

To decide whether the impaired hyperglycemic response was due primarily to the loss of renal mass or to metabolic consequences of renal failure (uremia), the following changes were made in the experimental design: a) rats were nephrectomized $2 \mathrm{~h}$ after instead of $14 \mathrm{~h}$ before giving NMMAA, in order to reduce the duration of the anephric state; and $b$ ) rats whose ureters were ligated $2 \mathrm{~h}$ after NMMAA intoxication were included in the study to serve as anuric controls with lidney tissue present. The differences in blood glucose concentration between the acutely nephrectomized rats and the sham-operated controls (Table 3) were similar to those observed in the previous experiment. In addition, the rats with ligated ureters initially developed a hyperglycemia similar to that in the controls; only at the sixteenth hour after intoxication, i.e. $14 \mathrm{~h}$ after ureteral ligation, was their blood glucose concentration significantly lower than in the controls, but still much higher than in the nephrectomized animals (Table 3 ).

\section{Discussion}

\section{Effect of NMMAA intoxication on gluconeogenic} capacity of renal cortex

The administration of NMMAA to rats caused an increase in the capacity of the renal cortex to produce glucose from endogenous and appropriate exogenous substrates. In contrast to its effect when given in vivo, NMMAA added to the incubation medium inhibited rather than stimulated renal glucose production. Therefore, the stimulation of gluconeogenesis in intoxicated animals is apparently not due to a direct effect of NMMAA on renal cortical tissue, but presumably represents a metabolic consequence of the induced diabetic syndrome.

The initiating factor in the diabetic animal could be the known deficiency of biologically active insulin [9]. Insulin deficiency produced by various means has been shown to stimulate gluconeogenesis both in the liver and the kidney. In livers taken from rats treated by anti-insulin serum, a pattern of metabolic intermediates consistent with an accelerated rate of gluconeogenesis has been observed [27]. Furthermore, Jefferson et al. [12] have found an increased conversion of ${ }^{14} \mathrm{C}$ lactate into glucose in the isolated perfused livers from rats similarly treated. In alloxan diabetes in the rat, net glucose production and conversion of labeled alanine to glucose by liver slices are increased [15], as is the capacity of kidney cortical slices to synthesize glucose from pyruvate $[26,14]$, glutamate, succinate [14] and $\alpha$-ketoglutarate [15].

Besides insulin deficiency, the metabolic acidosis developing in NMMAA diabetic rats [9] could contribute to stimulate renal gluconeogenesis. In rats rendered acidotic by $\mathrm{NH}_{4} \mathrm{Cl}$ feeding, kidney cortex slices incubated with suitable substrates show an increased gluconeogenic capacity $(7,1)$, presumably due to an increased phosphoenolpyruvate-carboxykinase (PEPCK) activity [7, 2, 10].

Kamm and Cahill [15] have proposed that the diabetic state per se may not increase renal gluconeogenesis and that the acid-base status is the major determinant of renal glucose production. However, in NMMAA diabetes, we found the rate of gluconeogenesis from fructose to be increased. This indicates a stimulation of the gluconeogenic pathway between the triose-phosphates and glucose, i.e. at a level which is not affected by metabolic acidosis [7]. Therefore, metabolic acidosis cannot be the only factor responsible for the enhanced renal gluconeogenesis observed after NMMAA. The stimulation of a rate-limiting step beyond the PEPCK catalyzed reaction may be related to the increased glucose-6-phosphatase activity observed in the kidneys of alloxan diabetic rats [6].

Another difference between renal gluconeogenesis 
in NMMAA diabetes and in metabolic acidosis pertains to the conversion of glutamine into glucose. In the acidotic kidney, Goodman et al. [7] found an increased rate of gluconeogenesis both from $\alpha$-ketoglutarate and from glutamine. They have proposed [7] that metabolic acidosis directly enhances conversion of $\alpha$-ketoglutarate to glucose by activating PEPCK, and that the resultant decrease in intracellular glutamate or one of its metabolites in turn activates the phosphatedependent glutaminase, thereby increasing glucose and ammonia production from glutamine. In NMMAA diabetes we found gluconeogenesis from $\alpha$-ketoglutarate to be stimulated without a concomitant increased conversion of glutamine to glucose. We conclude that in this condition, the gluconeogenic flux from $\alpha$-ketoglutarate does not control the rate of the reactions generating $\alpha$-ketoglutarate from glutamine.

\section{Effect of nephrectomy or ureteral ligation on NMMAA-induced hyperglycemia}

Hyperglycemia induced by NMMAA was drastically reduced in nephrectomized rats, irrespective of the duration of the anephric state. On the contrary, acute anuria following bilateral ureteral ligation did not prevent a normal rise in blood glucose concentration. Thus, the impaired hyperglycemic response in nephrectomized animals appears to be primarily related to the absence of renal tissue and not to a humoral change resulting from renal failure (uremia).

An additional role of uremia is suggested by the significantly lower blood sugar level in rats with ligated ureters than in controls $14 \mathrm{~h}$ after ligating the ureters. However, the interpretation of this difference is open to question because of a possible impairement of renal metabolism at this time, due to hydronephrosis.

Provided there is no larger peripheral utilization of glucose in nephrectomized than in intact animals, the smaller increase in blood glucose after NMMAA in the former should reflect a depressed glucose production in the body. Both from a theoretical point of view and from quantitative data on the in vivo synthesis of glucose by the kidney, it seems reasonable to hypothesize that at least part of this defect in glucose formation may be ascribed to the absence of renal gluconeogenesis.

On theoretical grounds, it has been estimated that the kidneys may supply as much new glucose to the body as the liver itself [16]. Actual measures of the balance of glucose across the kidney in the dog have yielded conflicting results $[18,4,21,20]$. Most recent studies negate any net renal glucose production in vivo, even after the induction of metabolic acidosis $(4,21$, 20], a condition where renal gluconeogenesis is known to be stimulated in vitro $[8,4]$. On the other hand, both in the dog [13] and in man [19], there are indications that the kidneys become a source of glucose for other tissues after a prolonged starvation. Furthermore, it has been shown that in alloxan diabetic rats the rapid fall of blood glucose concentration occuring after total evisceration is largely suppressed if the renal pedicles are left unligated during the evisceration procedure [24], a finding pointing to an important role of the kidney in the overall production of glucose in the body.

In summary, our observations demonstrate first that the gluconeogenic capacity of the renal cortex from NMMAA treated rats is enhanced, and second. that the presence of the kidneys is mandatory for the full development of the drug-induced hyperglycemia. We tentatively suggest that in vivo the kidneys might release a sizeable amount of glucose into the circulation, thereby sustaining the blood glucose level. This interpretation does not rule out alternative explanations of the effect of nephrectomy on the development of NMMAA hyperglycemia. In particular, the kidneys, whose capacity to extract insulin from blood and to degrade it is well documented [22], might be a site of abnormal insulin inactivation allegedly responsible for insulin deficiency in NMMAA diabetes [9]. According to this hypothesis, removal of the kidneys would result in an "insulin sparing effect", which could in part explain the diminished hyperglycemic response to NMMAA in nephrectomized rats.

Acknowledgements. The author is indebted to Dr. R. Guidoux for helpful advice. He also expresses thanks to Misses M. Petter, M.F. Nicolet, and R. Bally for their skilled technical assistance.

\section{References}

1. Alleyne, G.A.O.: Renal metabolic response to acidbase changes. II. The early effects of metabolic acidosis on renal metabolism in the rat. J. clin. Invest. 49, 943-951 (1970).

2. Alleyne, G.A.O., Scullard, G.H.: Renal metabolic response to acid-base changes. I. Enzymatic control of ammoniagenesis in the rat. J. clin. Invest. 48, 364$370(1969)$.

3. Benoy, M.P., Elliott, K.A.C.: The metabolism of lactic acid and pyruvic acid in normal and tumor tissue. Biochem. J. 31, 1268-1275 (1937).

4. Churchill, P.C., Malvin, R.L. : Relation of renal gluconeogenesis to ammonia production in the dog. Amer. J. Physiol. 218, $241-245$ (1970).

5. Deutsch, W.: An improvement of Warburg's method for cutting tissue slices for respiratory experiments. J. Physiol. (London) 87, 56P (1935).

6. Froesch, E.R., Ashmore, J., Renold, A.E.: Comparison of renal and hepatic effects of fasting, cortisone administration and glucose infusion in normal and adrenalectomized rats. Endocrinology 62, 614-620 (1958).

7. Goodman, A.D., Fuisz, R.E., Cahill, G.F., Jr.: Renal gluconeogenesis in acidosis, alkalosis and potassium deficiency: its possible role in regulation of renal ammonia production. J. clin. Invest. 45, 612-619 (1966).

8. Goorno, W.E., Rector, F.C., Seldin, D.W.: Relation of renal gluconeogenesis to ammonia production in the dog and rat. Amer. J. Physiol. 213, 969-974 (1967).

9. Guidoux, R.: Effets diabétogènes des diurétiques thiazidiques et du solvant $\mathrm{N}$-monométhylamide de l'acide acétique chez le rat. Diabetologia 5, 11-21 (1969). 
10. Hems, D.A., Brosnan, J.T.: Effects of metabolic acidosis and starvation on the content of intermediary metabolites in rat kidney. Biochem. J. 123, 391-397 (1971).

11. Huggett, A.St.G., Nixon, D.A.: Use of glucose oxidase, peroxidase and o-dianisidine in determination of blood and urinary glucose. Lancet 1957 II, 368370 .

12. Jefferson, L.S., Exton, J.H., Butcher, R.W., Sutherland, E.W., Park, C.R.: Role of adenosine $3^{\prime}, 5^{\prime}$ monophosphate in the effects of insulin and antiinsulin serum on liver metabolism. J. biol. Chem. 243, $1031-1038$ (1968).

13. Jonsson, A., Madison, L.L.: Evidence that the kidneys become a source of glucose for other tissues after fourteen days of starvation. Diabetes 17, 305 (1968).

14. Joseph, P.K., Subrahmanyam, K. : Effect of growth hormone, insulin, thyroxine and cortisone on renal gluconeogenesis. Arch. Biochem. Biophys, 127, 288291 (1968).

15. Kamm, D.E., Cahill, G.F., Jr.: Effect of acid-base status on renal and hepatic gluconeogenesis in diabetes and fasting. Amer. J. Physiol. 216, 1207-1212 (1969).

16. Krebs, H.A.: The Croonian lecture, 1963. Gluconeogenesis. Proc. roy. Soc. B. 159, 545-564 (1964).

17. Krebs, H. A., Henseleit, K. : Untersuchungen über die Harnstoffbildung im Tierkörper. Z. physiol. Chem. 210, 33-66 (1932).

18. Mc Cann, W.P., Jude, J.R.: The synthesis of glucose by the kidney. Bull. Johns Hopk. Hosp. 103, 77-93 (1958).

19. Owen, O.E., Felig, P., Morgan, A.P., Wahren, J., Cahill, G.F., Jr.: Liver and kidney metabolism during prolonged starvation. J. elin. Invest. 48, 574-583 (1969).
20. Roxe, D.M.: Renal gluconeogenesis after $\mathrm{NH}_{4} \mathrm{Cl}$, $\mathrm{NaHCO}_{3}$, hypoglycemia or pregnancy. Amer. J. Physiol. 222, 55-60 (1972).

21. Roxe, D.M., Disalvo, J., Balagura-Baruch, S.: Renal glucose production in the intact dog. Amer. J. Physiol. 218, 1676-1681 (1970).

22. Rubenstein, A.H., Spitz, I.: Role of the kidney in insulin metabolism and excretion. Diabetes 17, 161169 (1968).

23. Scrutton, M.C., Utter, M.F.: The regulation of glycolysis and gluconeogenesis in animal tissues. Ann. Rev. Biochem. 37, 249-302 (1968).

24. Smith, O.K., Long, C.N.H.: Renal gluconeogenesis in eviscerated diabetic rats. Proc. nat. Acad. Sci. U.S.A. 68, 1618-1622 (1971).

25. Snedecor, G.W., Cochran, W.G.: Statistical methods, sixth edition. Ames: The Iowa State University Press, 1967.

26. Teng, C.T.: Studies on carbohydrate metabolism in rat kidney slices. II. Effect of alloxan diabetes and insulin administration on glucose uptake and glucose formation. Arch. Biochem. Biophys. 48, 415-423 (1954).

27. Williamson, J.R.: Effects of fatty acids, glucagon and antiinsulin serum on the control of gluconoogenesis and ketogenesis in rat liver. Adv. Enzyme Regul. 5, $229-255$ (1967).

Dr. P.B. Iynedjian

Institut de Pharmacologie

Université de Lausanne

21, Rue de Bugnon

CH-1011 Lausanne 